\title{
Review Article \\ Zinc in Keratinocytes and Langerhans Cells: Relevance to the Epidermal Homeostasis
}

\author{
Youichi Ogawa (D), Manao Kinoshita, Shinji Shimada, and Tatsuyoshi Kawamura \\ Department of Dermatology, Faculty of Medicine, University of Yamanashi, Yamanashi 409-3898, Japan \\ Correspondence should be addressed to Youichi Ogawa; yogawa@yamanashi.ac.jp
}

Received 24 September 2018; Accepted 10 November 2018; Published 9 December 2018

Guest Editor: Toshiyuki Fukada

Copyright ( 2018 Youichi Ogawa et al. This is an open access article distributed under the Creative Commons Attribution License, which permits unrestricted use, distribution, and reproduction in any medium, provided the original work is properly cited.

\begin{abstract}
In the skin, the epidermis is continuously exposed to various kinds of external substances and stimuli. Therefore, epidermal barriers are crucial for providing protection, safeguarding health, and regulating water balance by maintaining skin homeostasis. Disruption of the epidermal barrier allows external substances and stimuli to invade or stimulate the epidermal cells, leading to the elicitation of skin inflammation. The major components of the epidermal barrier are the stratum corneum (SC) and tight junctions (TJs). The presence of zinc in the epidermis promotes epidermal homeostasis; hence, this study reviewed the role of zinc in the formation and function of the SC and TJs. Langerhans cells (LCs) are one of the antigen-presenting cells found in the epidermis. They form TJs with adjacent keratinocytes (KCs), capture external antigens, and induce antigen-specific immune reactions. Thus, the function of zinc in LCs was examined in this review. We also summarized the general knowledge of zinc and zinc transporters in the epidermis with updated findings.
\end{abstract}

\section{Introduction}

The epidermis is the outermost layer of the skin and is thus continuously exposed to various kinds of external substances and stimuli that can lead to potential harm. To counteract these risks and maintain homeostasis, the epidermis provides a barrier against the external environment. The importance of preserving epidermal homeostasis is evidenced by a reduction in the development of atopic dermatitis (AD) when moisturizer is applied to the skin during the neonatal period $[1,2]$. Reports also suggest that skin barrier disruption leads not only to the development of AD but also to other allergic diseases such as asthma, food allergies, and allergic rhinitis $[3,4]$.

The epidermis is composed predominantly of keratinocytes (KCs) plus a small number of Langerhans cells (LCs), melanocytes, and epidermal-resident memory $\mathrm{T}$ cells, as well as others. The murine epidermis also contains unique dendritic epidermal T cells, a type of $\gamma \delta \mathrm{T}$ cells. The epidermal KCs are categorized into four layers, namely, the stratum basale, stratum spinosum, stratum granulosum (SG), and stratum corneum (SC). A functional epidermal barrier depends on the existence of the SC and tight junctions (TJs) formed in the SG (Figure 1) [5, 6]. LCs can link with KCs to form TJs (Figure 1) [7,8].

The human body contains 2-3g of zinc ( $\mathrm{Zn})$, with approximately $5 \%$ of the total $\mathrm{Zn}$ found in the skin [9]. The concentration of $\mathrm{Zn}$ is higher in the epidermis than in the dermis and subcutaneous tissue, which may be due to the $\mathrm{Zn}$ requirement for active proliferation and differentiation of KCs [10]. Zn facilitates over 1000 enzymatic reactions and is indispensable for over 2000 transcriptional activities [11-13]. Zn finger proteins are involved in various physiological reactions [14-16]. Moreover, approximately $10 \%$ of human proteins bind to $\mathrm{Zn}$ [17]. Therefore, the dysregulation of epidermal $\mathrm{Zn}$ levels due to nutritional deficiency or genetic abnormalities of $\mathrm{Zn}$ transporters affects various enzymatic reactions, transcriptional activities, and $\mathrm{Zn}$ finger protein functions in the epidermis, leading to the disruption of skin homeostasis [18-20]. This review is aimed at highlighting the association between $\mathrm{Zn}$ and epidermal barrier function to understand the importance of $\mathrm{Zn}$ in skin immunity. We also summarize the function of $\mathrm{Zn}$ and $\mathrm{Zn}$ transporters in the epidermis and epidermal cells. 


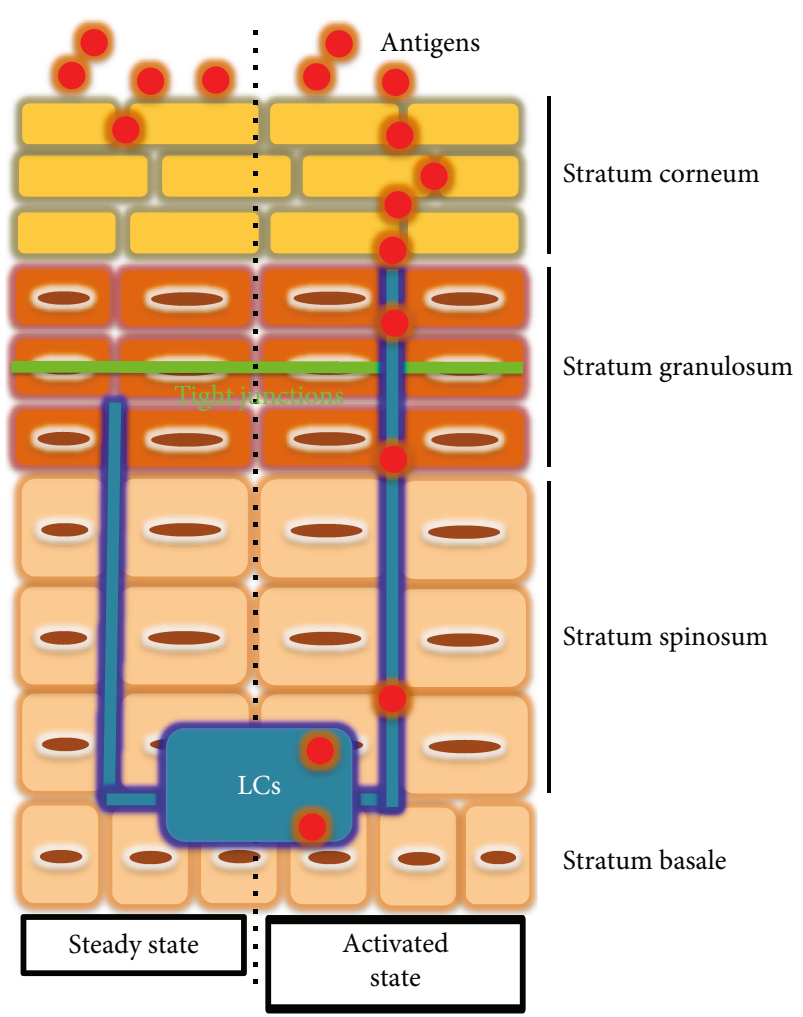

Figure 1: Structure of the epidermis. The epidermal KCs are categorized into four layers, namely, the stratum basale, stratum spinosum, stratum granulosum (SG), and stratum corneum (SC). A functional epidermal barrier depends on the existence of the SC and tight junctions (TJs) formed in the SG. LCs can link with KCs to form TJs. In steady state (left), LC dendrites lie beneath the TJs. Upon activation (right), LCs elongate their dendrites to penetrate the KC TJs by forming tricellulin-dependent TJs between KC-LC-KC. The elongated dendrites are able to reach beneath the $\mathrm{SC}$ and take up Ag from the extra-TJ environment without destroying barrier integrity. The original figure was published in [7].

\section{Zinc and the Epidermal Barrier}

The epidermal barrier function depends largely on the presence of SC and TJs formed in the SG $[4,21]$. In this respect, homeostasis of the epidermis depends on normal KC differentiation (keratinization). LCs, a type of tissueresident macrophages, also form TJs with KCs through linkages with KCs [7]. Most of the skin is covered with stratified epithelia that have both SC and TJs. However, skin appendages such as hair follicles and sweat glands lack SC, so TJs are the sole barrier structure in the skin appendages. The sections below summarized the involvement of $\mathrm{Zn}$ in the formation and function of SC and TJs.

2.1. Stratum Corneum. The outer layer of the SC consists of a cornified layer made of flattened and denucleated KCs (or corneocytes) and a SC-specific barrier structure called the cornified envelope that replaces the $\mathrm{KC}$ cell membranes. Through the process of terminal differentiation, SG KCs produce two membrane-circumscribed granules, keratohyalin granules and lamellar bodies. The former contains "intracellular" components of the SC such as filaggrin (FLG), loricrin, and keratin filaments, whereas the latter contains "extracellular" components such as lipids, corneodesmosin, and kallikreins. All of these intracellular and extracellular proteins are crucial for the formation and/or function of the epidermal barrier [21].

2.1.1. Zinc and Filaggrin and Its Metabolism. Among the components of keratohyalin granules, FLG has a crucial role in maintaining normal epidermal barrier function. FLG-deficient mice show an impaired SC barrier function and develop spontaneous dermatitis [22, 23]. Studies have shown that loss-of-function mutations in the FLG gene are strongly associated with the development of $\mathrm{AD}$ and ichthyosis vulgaris $[24,25]$. These mutations were shown to range from 25 to $50 \%$ in the Northern European and Asian populations with these ailments $[25,26]$. Moreover, FLG gene mutations were demonstrated as the strongest risk factor for $\mathrm{AD}$ in the genome-wide association studies (GWAS) [27]. These indicate the critical involvement of FLG in AD pathogenesis mediated by the disruption of the epidermal barrier.

FLG is produced in the SG as profilaggrin (FLG polymer) and is stored in keratohyalin granules. At the transition to the $\mathrm{SC}$, the polymer is processed to the monomer by proteases such as Prss8 and SASPase $[28,29]$ and then binds to keratin and forms the fundamental structure of the corneocytes. At the outermost layer of the SC, FLG is citrullinated by peptidylarginine deiminase and then dissociated from keratin filaments [30]. These dissociated FLG are degraded to free amino acids, including glutamine, arginine, and histidine. The FLG-derived histidine-rich proteins are converted into urocanic acid (UCA) and pyrrolidine carboxylic acid (PCA) by proteases. UCA absorbs ultraviolet, maintains the acidic $\mathrm{pH}$, and suppresses excess LC activation [31, 32]. PCA is a source of natural moisturizing factors. As a result, FLG is indispensable to the framework of SC and its metabolites are important for maintaining the epidermal barrier function (Figure 2).

$\mathrm{Zn}$ is involved in the regulation of FLG expression as well as its metabolism. It facilitates FLG production by increasing the activity of Prss8 [33]. Alternatively, Zn can also suppress FLG metabolism by decreasing PAD activity [34]. Moreover, $\mathrm{Zn}$ is required for histidine conversion to UCA [35] (Figure 2). Propionibacterium acnes ( $P$. acnes) induce excess $\mathrm{KC}$ proliferation and FLG expression in the epidermis through the induction of IGF-1, which activates the IGF-1 receptor (IGF-1R) on KCs. This causes follicular plugging that is frequently observed in patients with acne vulgaris. In these cases, $\mathrm{Zn}$ helps to maintain homeostasis by directly suppressing the induction of IGF-1 and IGF-1R and the overexpression of FLG [36].

OVO-like proteins (OVOLs) are transcribed from ubiquitously conserved genes encoding a $\mathrm{C} 2 \mathrm{H} 2$ zinc finger transcription factor in mammals [37]. Mutations in the OVOL1 gene, as well as the FLG gene, were demonstrated as a risk factor for AD in the GWAS [38-40]. Consistent with this finding, Ovol1-knockout mice show rapid disruption of the epidermal barrier [41]. OVOL1 regulates transcription 


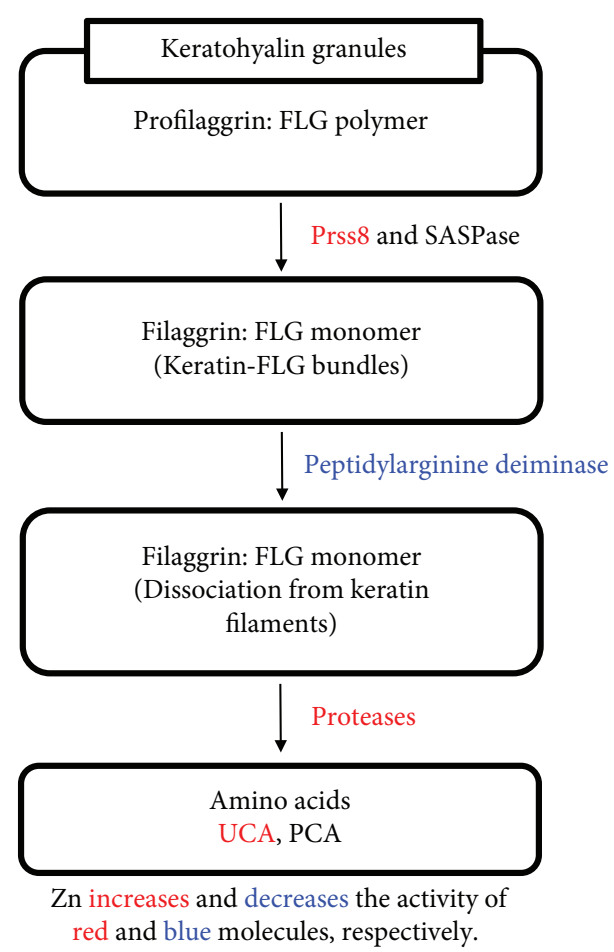

FIGURE 2: Filaggrin and its metabolism. FLG is produced in the SG as profilaggrin (FLG polymer) and is stored in keratohyalin granules. At the transition to the SC, the polymer is processed to the monomer by proteases such as Prss8 and SASPase and then binds to keratin and forms the fundamental structure of the corneocytes. At the outermost layer of the SC, FLG is citrullinated by peptidylarginine deiminase and then dissociated from keratin filaments. These dissociated FLG are degraded to free amino acids, including glutamine, arginine, and histidine. The FLG-derived histidine-rich proteins are converted into urocanic acid (UCA) and pyrrolidine carboxylic acid (PCA) by proteases. Zn facilitates FLG production by increasing the activity of Prss8. Alternatively, $\mathrm{Zn}$ can also suppress FLG metabolism by decreasing PAD activity. Moreover, $\mathrm{Zn}$ is required for histidine conversion to UCA.

in the nucleus by binding to p300, which is a member of the histone acetyltransferase (HAT) family and contains the Zn finger motif [42]. Additionally, HAT activity of p300 is negatively regulated by histone deacetylases (HDACs), which are Zn-dependent hydrolases [42]. Thus, OVOL1 expression and activity are regulated by $\mathrm{Zn}$ and $\mathrm{Zn}$-related epigenetic enzymes. Aryl hydrocarbon receptor (AHR) is a ubiquitous ligand-activated transcription factor that is activated by both endogenous and exogenous ligands. AHR activation induces nuclear translocation of OVOL1, leading to the upregulation of FLG expression [43, 44]. Given this, it is evident that $\mathrm{Zn}$ and various $\mathrm{Zn}$ finger proteins are involved in the regulation of FLG expression.

2.1.2. Zinc and Cornified Envelope, Intercellular Lipid Lamellae, and Corneodesmosome. The cornified envelope (CE) is formed of keratins enclosed within an insoluble protein shell just beneath the corneocyte cell membrane [45]. It provides a solid physical barrier and consists of a $10 \mathrm{~nm}$ thick layer of highly cross-linked insoluble proteins, such as involucrin, envoplakin, periplakin, loricrin, and small proline-rich protein. A $5 \mathrm{~nm}$ thick layer of intercellular lipid lamellae composed of ceramides, free fatty acids, and cholesterol is covalently bound to these proteins. Adhesion between corneocytes is assumed to occur by the desmosome apparatus (corneodesmosome), composed of desmosomal cadherin, armadillo proteins, and plakins. The CE, intercellular lipid lamellae, and corneodesmosome are essential for effective physical and water barrier functions in the epidermis. The role of $\mathrm{Zn}$ in the formation and function of these proteins has not yet been elucidated.

2.1.3. Zinc and Corneocyte Desquamation. Shedding of corneocytes at the outermost layer of the SC is called desquamation and is an important step for maintaining epidermal homeostasis and preventing hyperkeratosis. This step is primarily assumed by a proteolytic cleavage of kallikrein(KLK-) related peptidases. Out of 15 KLK proteins, human KCs express nearly all of them [46]. Among these KLKs, corneocyte desquamation is mainly conducted by KLK5, KLK7, and KLK14 [47]. The proteolytic activity is dependent on $\mathrm{pH}$ in the SC and is regulated by a cocktail of protease inhibitors, including lymphoepithelial Kazal-type 5 serine protease inhibitor (LEKTI) encoded by the serine protease inhibitor Kazal-type 5 (SPINK5) [48]. Importantly, the proteolytic activity of KLK5, KLK7, and KLK14 is impaired in the presence of $\mathrm{Zn} \mathrm{[49-51].} \mathrm{Furthermore,} \mathrm{the} \mathrm{expression} \mathrm{of} \mathrm{several}$ KLK-related peptidases, including KLK5 and KLK7, is negatively regulated by transcriptional factor specificity protein 1 (Sp1), a C2H2-type $\mathrm{Zn}$ finger protein [52].

Several reports demonstrated the association between $\mathrm{AD}$ and $\mathrm{Zn}$ deficiency in humans and mice [53-55]. Consistent with this finding, the skin $\mathrm{pH}$ is increased in patients with $\mathrm{AD}$ [56], possibly due to the reduced UCA production caused by Zn deficiency (see Section 2.1.1). Additionally, Sp1 expression is decreased in the epidermis of patients with $\mathrm{AD}$ [52], and, as a consequence, KLK activity is often enhanced. Since KLKs process prointerleukin- (IL-) $1 \alpha$ and IL- $1 \beta$ that are abundantly stored in the corneocytes to active forms, this enhanced KLK activity leads to skin inflammation [57]. Additionally, KLK5 and KLK14 activate proteinaseactivated receptor- (PAR-) 2, which is a G-protein-coupled receptor expressed on KCs, leading to the elicitation of itch common with $\mathrm{AD}$ [58]. Collectively, $\mathrm{Zn}$ suppresses excess inflammation and itching by inhibiting excess KLK activity. This action helps to maintain the epidermal barrier by suppressing IL-1-mediated FLG downregulation [57].

2.2. Zinc and Tight Junctions. TJs that are formed in the SG seal the intercellular spaces between SG KCs, thereby regulating the movement of water and inorganic ions via the paracellular pathway [59]. The major components of TJs are the transmembrane claudin proteins. Among the claudins expressed in the epidermis, claudin-1 is most critical for the formation and function of TJs, as confirmed in claudin-1knockout mice, which showed severe dehydration and death soon after birth without modulating SC formation [60]. Providing further support to the importance of claudin-1, the expression is decreased in the epidermis of patients with 
$\mathrm{AD}$ [61]. Other TJ components include transmembrane proteins such as occludin, JAM-A, tricellulin, and angulins and the intracellular scaffold proteins ZO-1, ZO-2, and ZO-3.

The role of $\mathrm{Zn}$ in the formation of TJs has been studied in the intestinal epithelium, but less so in the epidermis. For example, it has been reported that the chelation of intracellular Zn by TPEN ( $N, N, N^{\prime}, N^{\prime}$-tetrakis(2-pyridylmethyl)ethylenediamine) downregulates occludin and claudin-3, leading to TJ disruption in the intestinal epithelium [62]. It might be interesting to investigate the association between $\mathrm{Zn}$ deficiency in the epidermis and altered expression of TJ-associated proteins.

Zn finger E-box-binding homeobox- (ZEB-) 2 (also called SIP1) is a nuclear transcription factor that has $\mathrm{C} 2 \mathrm{H} 2-$ type Zn finger domains. Epidermal KC-specific ZEB-2 overexpression in mice showed epidermal barrier impairment along with the loss of expression of occludin and claudin-4 [63]. This suggests that the $\mathrm{Zn}$ finger protein, ZEB-2, negatively regulates the expression of occludin and claudin- 4 . The $\mathrm{Zn}$ endopeptidase meprin $\beta$ is expressed in the SG KCs just below the SC. Meprin $\beta$ is activated by KLK4 and facilitates proliferation and terminal differentiation of SG KCs, thereby contributing to the proper SC formation [64].

2.3. Epidermal Barrier Dysfunction and Th2 Response. Zn deficiency is known to drive Th2-type immune response and is associated with $\mathrm{AD}$ [65]. This suggests that $\mathrm{Zn}$ deficiency contributes to the disruption of the epidermal barrier through the downregulation of formation and/or function of SC and TJs. Epidermal barrier dysfunction allows external substances and stimuli to invade the epidermis and leads to the production of KC-derived Th2-inducing cytokines, including thymic stromal lymphoproteins (TSLP) and IL-33. TSLP downregulates FLG expression while IL-33 downregulates both FLG and claudin-1 expression [66-68]. Major Th2 cytokines, IL-4 and IL-13, downregulate the expression of FLG, the CE components (loricrin and involucrin), cell adhesion molecules (ZO-1), and ceramide lipids. IL-4 also inhibits the nuclear translocation of OVOL1, leading to the downregulation of FLG expression (see Section 2.1.1) [43]. IL-31, another Th2 cytokine, also downregulates FLG expression [69]. Taken together, epidermal barrier dysfunction, which is influenced by $\mathrm{Zn}$ deficiency, results in the disruption of skin homeostasis characterized by the Th2 immune response and vice versa.

\section{Zinc and Langerhans Cells}

LCs are antigen-presenting cells that occupy approximately $3 \%$ of the epidermis [70]. They were previously considered a subtype of dendritic cells (DCs) because of their ability to capture antigens (Ag), migrate to the draining lymph nodes (dLNs), and then present the Ag to T cells and initiate the immune response. However, recent evidence revealed that LCs originate from macrophage lineage of fetal liver progenitors and not from DC lineage [71-74]. Therefore, LCs are currently considered tissue-resident macrophages with the ability to migrate to the dLNs.
3.1. LCs and Tight Junctions. LCs express claudin-1 and form TJs with adjacent SG KCs [75]. As such, LCs are an important component of TJs to create an effective epidermal barrier. In steady state, LC dendrites lie beneath the TJs. Upon activation, LCs elongate their dendrites to penetrate the KC TJs by forming tricellulin-dependent TJs between KC-LC-KC. The elongated dendrites are able to reach beneath the SC and take up Ag from the extra-TJ environment without destroying barrier integrity (Figure 1) [7]. These LCs then induce Th2-type, but not Th1-type, humoral immune responses [8]. Furthermore, LCs take up KC-derived auto$\mathrm{Ag}$ and present it on their MHC class II. These LCs expand polyclonal Ag-specific regulatory $\mathrm{T}$ cells and keep peripheral tolerance against auto-Ag [76]. Therefore, LCs assume the dual role of TJ component and surveillance agent of foreign and auto-Ag.

3.2. LCs and Zinc Deficiency. The association between $\mathrm{Zn}$ and LCs was revealed by analysis of skin specimen from patients with acrodermatitis enteropathica (AE; OMIM 201100) [77]. $\mathrm{AE}$ is an autosomal recessive disease caused by mutations in the SLC39A4 gene that encodes ZRT/IRT-like protein 4 (ZIP4) [78]. ZIP4 is abundantly expressed in the apical side of the intestinal epithelium, thereby working as the primary gate absorbing $\mathrm{Zn}$ into the enterocytes. This absorbed $\mathrm{Zn}$ is subsequently transported to the bloodstream by $\mathrm{Zn}$ transporter 1 (ZnT1) [79, 80]. Therefore, ZIP4 dysfunction due to mutations results in decreased serum $\mathrm{Zn}$ levels. Interestingly, epidermal LCs were absent in AE skin lesions [77] (Figure 3). However, LCs were restored in the epidermis after patients were given $\mathrm{Zn}$ supplementation. These phenomena suggest that LCs disappeared from the epidermis when patients are deficient in $\mathrm{Zn}$, but the effect can be easily reversed.

The association between LC loss and the development of characteristic AE skin lesion was investigated using dietary Zn-deficient (ZD) and Zn-adequate (ZA) mice [77]. Consistent with observations in patients with $\mathrm{AE}$, epidermal LCs also disappeared in ZD mice (Figure 4).

"Allergic" contact dermatitis was significantly impaired in ZD mice compared with ZA mice. On the other hand, "irritant" contact dermatitis (ICD) was significantly enhanced in ZD mice compared to ZA mice. ICD is mediated by adenosine triphosphate (ATP), which is secreted by KCs in response to environmental irritants through lytic and nonlytic mechanisms [81-84]. As expected, ATP production from croton oil-applied skin was significantly increased in ZD mice compared with ZA mice. Additionally, ATP production from Pam 212 KCs (murine immortalized KCs) was significantly increased by incubation with TPEN. These data suggest that $\mathrm{KCs}$ in $\mathrm{ZD}$ mice produce more ATP than $\mathrm{KCs}$ in ZA mice [77].

ATP is a potent inflammation inducer. Therefore, the epidermis is equipped with a mechanism to prevent ATPmediated inflammation in the steady state. CD39 (ectonucleoside triphosphate diphosphohydrolase-1; ENTPD-1) plays a central role in ATP hydrolysis [83]. In the epidermis, CD39 is predominantly expressed in LCs, but not in KCs $[83,85,86]$. Thus, ATP is not hydrolyzed in the epidermis 


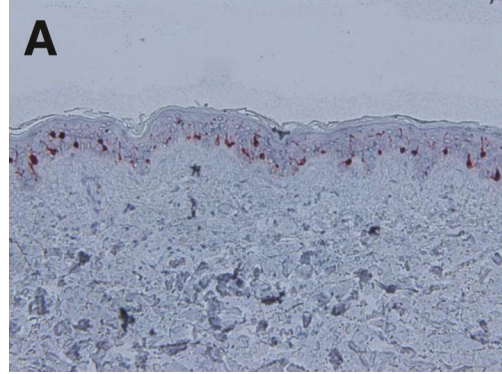

(a)

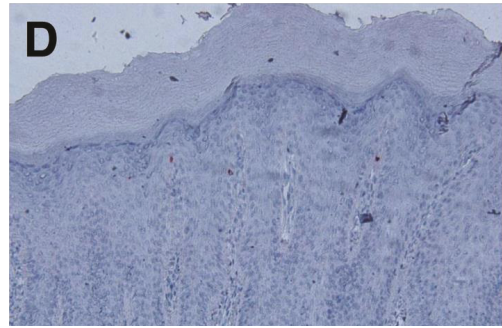

(d)

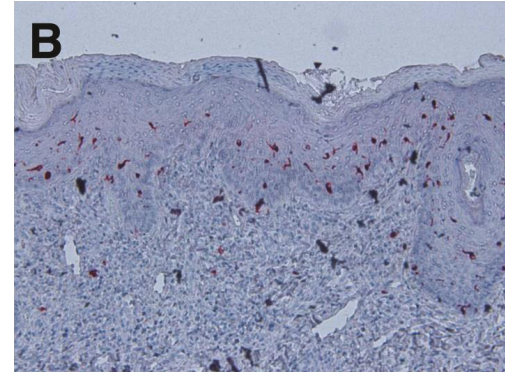

(b)

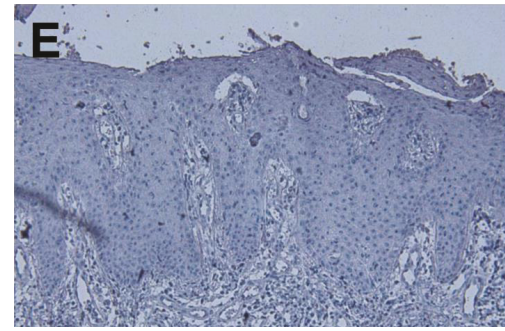

(e)

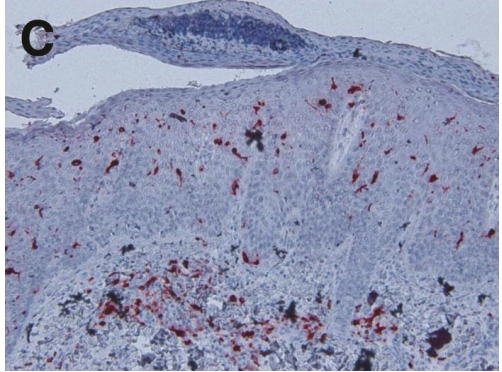

(c)

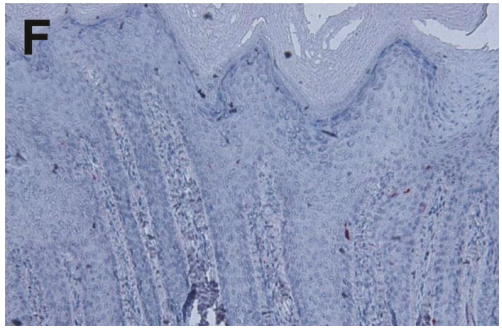

(f)

Figure 3: Loss of epidermal LCs in patients with AE. Immunohistochemical staining for langerin (red) in normal skin (a) and the erythematous lesions in atopic dermatitis (b), psoriasis vulgaris (c), or three AE (d-f) patients. Original magnification: 200x.

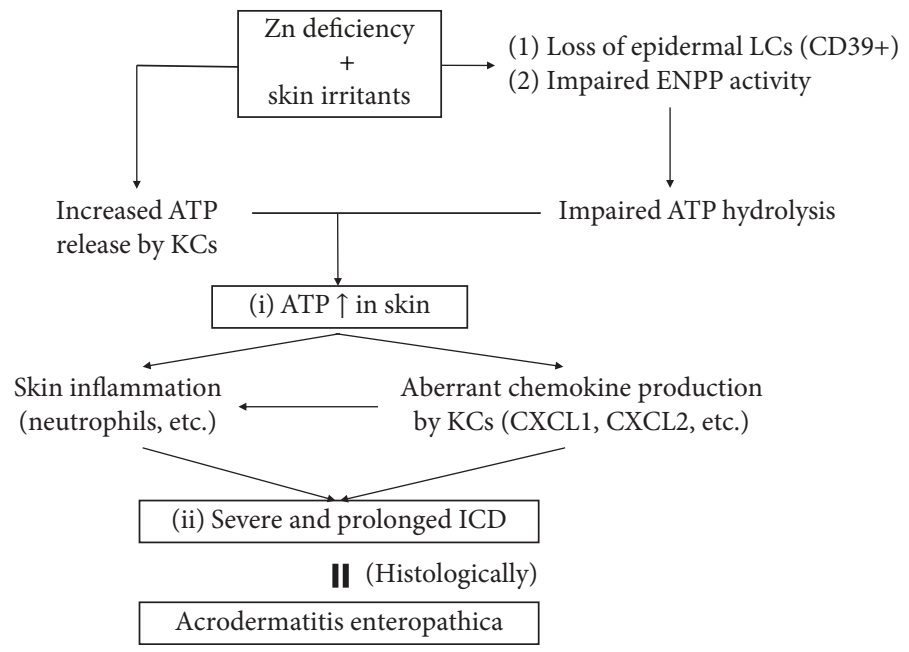

Figure 4: Model for the etiology of AE. (i) Skin irritants increase ATP release in the skin in Zn deficiency, due to increased ATP release by KCs, impaired ATP hydrolysis by LCs, and impaired ENPP activity. (ii) Increased ATP release induces severe and prolonged ICD via aberrant chemokine production by KCs and neutrophil-mediated skin inflammation. Histologically, cutaneous lesions in AE and ICD lesions in ZD mice demonstrate common histological features, such as subcorneal vacuolization and epidermal pallor.

of patients with $\mathrm{AE}$ and $\mathrm{ZD}$ mice, thereby eliciting ATPmediated ICD in skin. In line with this concept, characteristic AE skin lesions develop in anogenital and periorificial areas and distal portions of the extremities, where frequent contact with external irritants including feces, urine, saliva, food, shoes, or excessive sweating is expected.

Taken together, the nature of AE skin lesions is ICD mediated by (1) increased ATP production by ZD KCs and (2) disabling of ATP hydrolysis due to the loss of CD39-expressing LCs.
As described, CD39 (ENTPD-1) potently hydrolyzes ATP. However, there are three groups of molecules that hydrolyze ATP, including ENTPDs, ectonucleotide pyrophosphatase/phosphodiesterases (ENPPs), and alkaline phosphatase (ALP) $[87,88]$. The latter two molecules are Zn-dependent molecules. Among ENTPDs and ENPPs, ENTPD-1 (CD39), -2, -3, and -8 and ENPP-1, -2, and -3 aid in ATP hydrolysis. The expression of these molecules in LCs and KCs was not previously understood, with the exception of CD39. Thus, we determined that LCs strongly 
expressed CD39 and weakly expressed ENTPD-2 and ENPP-1, -2, and -3. Normal human epidermal KCs weakly expressed CD39, ENTPD-2 and -3, and ENPP-1 and -2. Neither LCs nor KCs expressed ENTPD-8 or ALP. Therefore, although LCs strongly express CD39, other ATPhydrolyzing molecules are weakly expressed in both LCs and KCs. KCs occupy approximately $97 \%$ of the epidermis, whereas LCs occupy approximately $3 \%$. Therefore, we determined the degree of contribution of LCs and KCs to ATP hydrolysis. ATP hydrolysis was impaired by approximately $80 \%$ in LC-depleted epidermal suspension compared with sham-sorted epidermal suspension. This suggests that LCs assume approximately $80 \%$ of epidermal ATP hydrolysis, whereas KCs assume the remaining 20\% [89].

Recently, it was demonstrated that Zn deficiency impairs the activity of ENPP-1 and ENPP-3, as well as ALP and CD73 [90]. As described, KCs weakly express ENPP-1 and ENPP-2. This explains one underlying mechanism by which ZD KCs increase ATP production.

3.3. LCs and Zinc Finger Proteins. In the steady state, LCs form the firm connections with adjacent KCs by claudin-1 and E-cadherin. Additionally, EpCAM (epithelial cell adhesion molecule) in mice and its human homolog, tumorassociated calcium signal transducer 2, also participate in this cell adhesion [91]. Claudin-1 and EpCAM colocalize in LCs [92]. Upon LC activation, LCs downregulate these adhesion molecules and then migrate to the dLNs. LCs upregulate ZEB-1 and ZEB-2 (see Section 2.2) during maturation, subsequently downregulating E-cadherin expression in LCs $[93,94]$. Additionally, downregulation of EpCAM in LCs impairs claudin-1 expression in LCs [92]. This suggests that $\mathrm{Zn}$ deficiency leads to LC retention in the epidermis. Nevertheless, the presence of LCs is reduced with $\mathrm{Zn}$ deficiency [77]. For LC development and survival, LC-derived, but not KC-derived, autocrine transforming growth factor beta (TGF- $\beta$ ) is crucial [95-98]. This latent secreted protein is processed and activated by $\alpha \mathrm{v} \beta 6$ and $\alpha \mathrm{v} \beta 8$ integrins on KCs and then is recognized by LCs [99-101]. In patients with $\mathrm{AE}$ and $\mathrm{ZD}$ mice, the epidermal expression of TGF- $\beta$ is strongly impaired, and thus, LCs are reduced [77]. However, the association between $\mathrm{Zn}$ deficiency and impaired epidermal TGF- $\beta$ expression is not fully understood.

Collectively, Zn deficiency in the epidermis results in (1) disruption of epidermal barrier function (see Section 2), (2) LC disappearance due to impaired epidermal TGF- $\beta$ expression, (3) impaired ATP hydrolysis due to the reduced number of CD39-expressing LCs and impaired ENPP activity, and (4) elicitation of ATP-mediated skin inflammation. Because of its importance, we are currently investigating the impact of LC loss on TJ development and function using AE skin specimens and ZD mice.

\section{Zinc and Zinc Transporters in the Epidermis}

The subject of $\mathrm{Zn}$ transporters in the epidermis has been widely reviewed by us and others [18-20]. Thus, here, we briefly summarized what is known and added recent findings. $\mathrm{Zn}$ is distributed to a higher degree in the epidermis than in the dermis. Within the epidermis, $\mathrm{Zn}$ is distributed primarily in the stratum spinosum [102]. LCs are present in the stratum spinosum, where $\mathrm{Zn}$ is found, and research suggests that LCs definitively require $\mathrm{Zn}$ for their survival and function [77].

The fundamental functions of $\mathrm{Zn}$ in the KCs are proliferation and anti-inflammation. KCs treated with nontoxic concentration of $\mathrm{Zn}$ increased their proliferation and survival [103]. Conversely, the chelation of intracellular $\mathrm{Zn}$ by TPEN facilitates $\mathrm{KC}$ apoptosis by activating caspase- 3 and DNA fragmentation [104]. Zn has been reported to suppress the production of tumor necrosis factor- $\alpha$, inducible nitric oxide synthase, and subsequent nitric oxide in KCs $[65,105,106]$. $\mathrm{Zn}$ also suppresses the expression of toll-like receptor 2 on KCs [107].

The rigorous $\mathrm{Zn}^{2+}$ regulation is conducted by $\mathrm{Zn}$ transporters (ZnTs and ZIPs) and metallothioneins (MTs) [108, 109]. So far, 10 ZnTs, 14 ZIPs, and 4 MTs were identified in humans $[110,111]$. ZnTs and ZIPs mediate Zn efflux and uptake, respectively. MTs are ubiquitously expressed throughout various types of cells and are predominantly distributed in the cytoplasm and to a lesser extent in the nuclei and lysosomes. MTs can bind to metal ion including $\mathrm{Zn}$ via a unique cysteine-rich amino acid sequence and essentially control the availability of $\mathrm{Zn}$ [112]. Among $24 \mathrm{Zn}$ transporters (10 ZnTs and $14 \mathrm{ZIPs}$ ), the function of only four $\mathrm{Zn}$ transporters (ZnT1, ZIP2, ZIP4, and ZIP10) in the epidermis or KCs has been elucidated so far.

$\mathrm{ZnT1}$ in KCs is involved in the development of epidermodysplasia verruciformis (EV; OMIM 226400), which is a rare autosomal-recessive skin disease that can lead to nonmelanoma skin cancers resulting from selective susceptibility to oncogenic human papillomaviruses (HPVs) [113]. In KCs, EVER1 and EVER2 proteins form a complex with ZnT1 primarily in the ER and to a lesser extent in the nuclear membrane and Golgi apparatus. This complex maintains $\mathrm{Zn}$ homeostasis, which inhibits activator protein-1 (AP-1) activation that promotes HPV replication. Patients with EV have mutations in either the EVER1 or EVER2 genes [114, 115]. The complex of ZnT1 and mutated EVERs increases free Zn transport in the nucleus and subsequently enhances AP-1 activity, leading to aberrant replication of EV-related oncogenic HPVs and thereby developing skin cancers.

ZIP2 is expressed on the differentiating KCs of humans and mice. Since ZIP2 knockdown in KCs decreases intracellular $\mathrm{Zn}$, suppresses KC differentiation, and downregulates involucrin expression, $\mathrm{Zn}$ taken up by $\mathrm{KC} \mathrm{ZIP} 2$ is required for proper $\mathrm{KC}$ differentiation and $\mathrm{CE}$ formation (also see Section 2.1.2) [102]. ZIP4 is expressed on the undifferentiating KCs of humans. Since ZIP4 knockdown in KCs decreases intracellular Zn, suppresses $\mathrm{KC}$ differentiation, downregulates the expression of FLG and involucrin, and impairs the activity of p63 that is a critical regulator of epidermal formation, $\mathrm{Zn}$ taken up by KC ZIP4 is required for proper $\mathrm{KC}$ differentiation and SC formation (also see Section 2.1) [116]. Murine ZIP10 is expressed on the epidermal progenitor cells of the outer root sheath of hair follicles. Therefore, ZIP10 depletion in keratin 14-expressing cells leads to a thin epidermis and a hypoplasia of hair follicles via downregulation of 
p63 activity [117]. The epidermal regulator p63 also controls the activity of ZNF750, a C2H2-type Zn finger protein. ZNF750 strongly regulates terminal epidermal differentiation. Thus, ZNF750 knockdown downregulates the expression of epidermal barrier-related proteins including FLG, loricrin, and SPINK5 [118]. In human skin, MT-1 and MT-2 are expressed in the actively proliferating KCs, such as the hair matrix, outer hair roots, and stratum basale [119]. Knockdown of both MT-1 and MT-2 in mice impairs KC proliferation [120]. MT expressions are upregulated in the hyperplastic KCs of inflamed skin lesions and skin cancers [121].

Collectively, Zn supports KC proliferation and survival. ZIP2 and ZIP4 are required for proper KC differentiation and subsequent epidermal barrier formation. ZIP10 is required for the successful epidermal formation. MTs are involved in $\mathrm{KC}$ proliferation.

\section{Conclusions and Perspectives}

Epidermal barrier homeostasis is the first line of defense for preventing the initiation of atopic march. SC and TJs are responsible for epidermal barrier function. $\mathrm{Zn}$ and $\mathrm{Zn}$ finger proteins regulate SC formation as well as its metabolism, while the contribution of $\mathrm{Zn}$ to TJ function is less well understood. However, when $\mathrm{Zn}$ is deficient, LCs are not present, and this important component of TJs is lacking. Therefore, $\mathrm{Zn}$ deficiency might lead to epidermal barrier dysfunction. Disruption of the epidermal barrier induces a Th2-type immune response by producing $\mathrm{KC}$-derived Th2-promoting cytokines and $\mathrm{T}$ cell-derived Th2 cytokines. Meanwhile, these Th2-related cytokines impair the structure and function of the SC and TJs. In this way, epidermal barrier disruptions trigger a negative spiral of inflammation. $\mathrm{Zn}$ homeostasis in cells, including KCs, is maintained by ZnTs, ZIPs, and MTs. MT-mediated Zn in KCs facilitates its proliferation. On the other hand, the function of ZnTs and ZIPs in KC biology is less understood, because only the function of $\mathrm{ZnT1}$, ZIP2, ZIP4, and ZIP10 has been elucidated from among 10 ZnTs and 14 ZIPs. The epidermis is composed of KCs, LCs, melanocytes, epidermal-resident memory $\mathrm{T}$ cells (TRMs), and others. The murine epidermis, but not the human epidermis, also contains dendritic epidermal T cells (DETCs), a type of $\gamma \delta \mathrm{T}$ cells. The role of $\mathrm{Zn}$ and $\mathrm{Zn}$ transporters in LCs, melanocytes, TRMs, and DETCs has not been analyzed to date. Additional research must be conducted to thoroughly understand the role of $\mathrm{Zn}$ and $\mathrm{Zn}$ transporters in maintaining healthy skin.

\section{Conflicts of Interest}

The authors declare no competing financial interest.

\section{References}

[1] K. Horimukai, K. Morita, M. Narita et al., "Application of moisturizer to neonates prevents development of atopic dermatitis," The Journal of Allergy and Clinical Immunology, vol. 134, no. 4, pp. 824-830.e6, 2014.
[2] E. L. Simpson, J. R. Chalmers, J. M. Hanifin et al., "Emollient enhancement of the skin barrier from birth offers effective atopic dermatitis prevention," The Journal of Allergy and Clinical Immunology, vol. 134, no. 4, pp. 818-823, 2014.

[3] J. M. Spergel and A. S. Paller, "Atopic dermatitis and the atopic march," The Journal of Allergy and Clinical Immunology, vol. 112, no. 6, pp. S118-S127, 2003.

[4] G. Egawa and K. Kabashima, "Multifactorial skin barrier deficiency and atopic dermatitis: essential topics to prevent the atopic march," The Journal of Allergy and Clinical Immunology, vol. 138, no. 2, pp. 350-358.e1, 2016, e351.

[5] M. J. Cork, S. G. Danby, Y. Vasilopoulos et al., "Epidermal barrier dysfunction in atopic dermatitis," The Journal of Investigative Dermatology, vol. 129, no. 8, pp. 1892-1908, 2009.

[6] A. De Benedetto, A. Kubo, and L. A. Beck, "Skin barrier disruption: a requirement for allergen sensitization?," The Journal of Investigative Dermatology, vol. 132, no. 3, pp. 949-963, 2012.

[7] A. Kubo, K. Nagao, M. Yokouchi, H. Sasaki, and M. Amagai, "External antigen uptake by Langerhans cells with reorganization of epidermal tight junction barriers," The Journal of Experimental Medicine, vol. 206, no. 13, pp. 2937-2946, 2009.

[8] T. Ouchi, A. Kubo, M. Yokouchi et al., "Langerhans cell antigen capture through tight junctions confers preemptive immunity in experimental staphylococcal scalded skin syndrome," The Journal of Experimental Medicine, vol. 208, no. 13, pp. 2607-2613, 2011.

[9] M. J. Jackson, "Physiology of zinc: general aspects," in Zinc in Human Biology, C. F. Mills, Ed., pp. 1-14, Springer, London, 1989.

[10] G. Michaelsson, K. Ljunghall, and B. G. Danielson, "Zinc in epidermis and dermis in healthy subjects," Acta DermatoVenereologica, vol. 60, no. 4, pp. 295-299, 1980.

[11] C. Andreini, I. Bertini, and G. Cavallaro, "Minimal functional sites allow a classification of zinc sites in proteins," PLoS One, vol. 6, no. 10, article e26325, 2011.

[12] C. Andreini and I. Bertini, "A bioinformatics view of zinc enzymes," Journal of Inorganic Biochemistry, vol. 111, pp. 150-156, 2012.

[13] J. M. Berg and Y. Shi, "The galvanization of biology: a growing appreciation for the roles of zinc," Science, vol. 271, no. 5252, pp. 1081-1085, 1996.

[14] T. Fukada, S. Yamasaki, K. Nishida, M. Murakami, and T. Hirano, "Zinc homeostasis and signaling in health and diseases: zinc signaling," Journal of Biological Inorganic Chemistry, vol. 16, no. 7, pp. 1123-1134, 2011.

[15] A. Klug, "The discovery of zinc fingers and their development for practical applications in gene regulation and genome manipulation," Quarterly Reviews of Biophysics, vol. 43, no. 1, pp. 1-21, 2010.

[16] J. H. Laity, B. M. Lee, and P. E. Wright, "Zinc finger proteins: new insights into structural and functional diversity," Current Opinion in Structural Biology, vol. 11, no. 1, pp. 39-46, 2001.

[17] C. Andreini, L. Banci, I. Bertini, and A. Rosato, "Counting the zinc-proteins encoded in the human genome," Journal of Proteome Research, vol. 5, no. 1, pp. 196-201, 2006.

[18] Y. Ogawa, T. Kawamura, and S. Shimada, "Zinc and skin biology," Archives of Biochemistry and Biophysics, vol. 611, pp. 113-119, 2016. 
[19] Y. Ogawa, M. Kinoshita, S. Shimada, and T. Kawamura, "Zinc and skin disorders," Nutrients, vol. 10, no. 2, 2018.

[20] B.-H. Bin, S. Hojyo, J. Seo et al., "The role of the Slc39a family of zinc transporters in zinc homeostasis in skin," Nutrients, vol. 10, no. 2, 2018.

[21] G. Egawa and K. Kabashima, "Barrier dysfunction in the skin allergy," Allergology International, vol. 67, no. 1, pp. 3-11, 2018.

[22] H. Kawasaki, K. Nagao, A. Kubo et al., "Altered stratum corneum barrier and enhanced percutaneous immune responses in filaggrin-null mice," Journal of Allergy and Clinical Immunology, vol. 129, no. 6, pp. 1538-1546.e6, 2012.

[23] S. P. Saunders, T. Moran, A. Floudas et al., "Spontaneous atopic dermatitis is mediated by innate immunity, with the secondary lung inflammation of the atopic march requiring adaptive immunity," The Journal of Allergy and Clinical Immunology, vol. 137, no. 2, pp. 482-491, 2016.

[24] C. N. A. Palmer, A. D. Irvine, A. Terron-Kwiatkowski et al., "Common loss-of-function variants of the epidermal barrier protein filaggrin are a major predisposing factor for atopic dermatitis," Nature Genetics, vol. 38, no. 4, pp. 441-446, 2006.

[25] F. J. D. Smith, A. D. Irvine, A. Terron-Kwiatkowski et al., "Loss-of-function mutations in the gene encoding filaggrin cause ichthyosis vulgaris," Nature Genetics, vol. 38, no. 3, pp. 337-342, 2006.

[26] T. Nomura, A. Sandilands, M. Akiyama et al., "Unique mutations in the filaggrin gene in Japanese patients with ichthyosis vulgaris and atopic dermatitis," The Journal of Allergy and Clinical Immunology, vol. 119, no. 2, pp. 434440, 2007.

[27] L. Paternoster, The EArly Genetics and Lifecourse Epidemiology (EAGLE) Eczema Consortium, M. Standl et al., "Multi-ancestry genome-wide association study of 21,000 cases and 95,000 controls identifies new risk loci for atopic dermatitis," Nature Genetics, vol. 47, no. 12, pp. 1449-1456, 2015.

[28] C. Leyvraz, R. P. Charles, I. Rubera et al., “The epidermal barrier function is dependent on the serine protease CAP1/Prss 8," The Journal of Cell Biology, vol. 170, no. 3, pp. 487-496, 2005.

[29] T. Matsui, K. Miyamoto, A. Kubo et al., "SASPase regulates stratum corneum hydration through profilaggrin-tofilaggrin processing," EMBO Molecular Medicine, vol. 3, no. 6, pp. 320-333, 2011.

[30] R. Nachat, M.-C. Méchin, H. Takahara et al., "Peptidylarginine deiminase isoforms 1-3 are expressed in the epidermis and involved in the deimination of K1 and filaggrin," Journal of Investigative Dermatology, vol. 124, no. 2, pp. 384-393, 2005.

[31] N. K. Gibbs, J. Tye, and M. Norval, "Recent advances in urocanic acid photochemistry, photobiology and photoimmunology," Photochemical \& Photobiological Sciences, vol. 7, no. 6, pp. 655-667, 2008.

[32] C. S. Leitch, E. Natafji, C. Yu et al., "Filaggrin-null mutations are associated with increased maturation markers on Langerhans cells," The Journal of Allergy and Clinical Immunology, vol. 138, no. 2, pp. 482-490.e7, 2016, e487.

[33] A. Shipway, H. Danahay, J. A. Williams, D. C. Tully, B. J. Backes, and J. L. Harris, "Biochemical characterization of prostasin, a channel activating protease," Biochemical and
Biophysical Research Communications, vol. 324, no. 2, pp. 953-963, 2004.

[34] P. Stenberg and B. Roth, "Zinc is the modulator of the calcium-dependent activation of post-translationally acting thiol-enzymes in autoimmune diseases," Medical Hypotheses, vol. 84, no. 4, pp. 331-335, 2015.

[35] J. M. Hsu and B. Rubenstein, "Effect of zinc deficiency on histidine metabolism in rats," The Journal of Nutrition, vol. 112, no. 3, pp. 461-467, 1982.

[36] O. Isard, A. C. Knol, M. F. Ariès et al., "Propionibacterium acnes activates the IGF-1/IGF-1R system in the epidermis and induces keratinocyte proliferation," The Journal of Investigative Dermatology, vol. 131, no. 1, pp. 59-66, 2011.

[37] A. Kumar, A. Bhandari, R. Sinha et al., "Molecular phylogeny of OVOL genes illustrates a conserved $\mathrm{C} 2 \mathrm{H} 2$ zinc finger domain coupled by hypervariable unstructured regions," PLoS One, vol. 7, no. 6, article e39399, 2012.

[38] T. Hirota, A. Takahashi, M. Kubo et al., "Genome-wide association study identifies eight new susceptibility loci for atopic dermatitis in the Japanese population," Nature Genetics, vol. 44, no. 11, pp. 1222-1226, 2012.

[39] L. Paternoster, M. Standl, C. M. Chen et al., "Meta-analysis of genome-wide association studies identifies three new risk loci for atopic dermatitis," Nature Genetics, vol. 44, no. 2, pp. 187-192, 2011.

[40] I. Marenholz, J. Esparza-Gordillo, F. Rüschendorf et al., "Meta-analysis identifies seven susceptibility loci involved in the atopic march," Nature Communications, vol. 6, no. 1, p. $8804,2015$.

[41] A. Teng, M. Nair, J. Wells, J. A. Segre, and X. Dai, "Straindependent perinatal lethality of Ovol1-deficient mice and identification of Ovol2 as a downstream target of Ovol1 in skin epidermis," Biochimica et Biophysica Acta (BBA) Molecular Basis of Disease, vol. 1772, no. 1, pp. 89-95, 2007.

[42] M. Nair, V. Bilanchone, K. Ortt, S. Sinha, and X. Dai, "Ovol 1 represses its own transcription by competing with transcription activator c-Myb and by recruiting histone deacetylase activity," Nucleic Acids Research, vol. 35, no. 5, pp. 16871697, 2007.

[43] G. Tsuji, A. Hashimoto-Hachiya, M. Kiyomatsu-Oda et al., "Aryl hydrocarbon receptor activation restores filaggrin expression via OVOL1 in atopic dermatitis," Cell Death and Disease, vol. 8, no. 7, article e2931, 2017.

[44] G. Tsuji, T. Ito, T. Chiba et al., "The role of the OVOL1OVOL2 axis in normal and diseased human skin," Journal of Dermatological Science, vol. 90, no. 3, pp. 227-231, 2018.

[45] A. Kalinin, L. N. Marekov, and P. M. Steinert, "Assembly of the epidermal cornified cell envelope," Journal of Cell Science, vol. 114, Part 17, pp. 3069-3070, 2001.

[46] N. Komatsu, M. Takata, N. Otsuki et al., "Expression and localization of tissue kallikrein mRNAs in human epidermis and appendages," The Journal of Investigative Dermatology, vol. 121, no. 3, pp. 542-549, 2003.

[47] M. Brattsand, K. Stefansson, C. Lundh, Y. Haasum, and T. Egelrud, "A proteolytic cascade of kallikreins in the stratum corneum," The Journal of Investigative Dermatology, vol. 124, no. 1, pp. 198-203, 2005.

[48] C. Deraison, C. Bonnart, F. Lopez et al., "LEKTI fragments specifically inhibit KLK5, KLK7, and KLK14 and control desquamation through a $\mathrm{pH}$-dependent interaction," 
Molecular Biology of the Cell, vol. 18, no. 9, pp. 36073619, 2007.

[49] M. Debela, P. Goettig, V. Magdolen, R. Huber, N. M. Schechter, and W. Bode, "Structural basis of the zinc inhibition of human tissue kallikrein 5," Journal of Molecular Biology, vol. 373, no. 4, pp. 1017-1031, 2007.

[50] M. Debela, P. Hess, V. Magdolen et al., "Chymotryptic specificity determinants in the $1.0 \mathrm{~A}$ structure of the zincinhibited human tissue kallikrein 7," Proceedings of the National Academy of Sciences of the United States of America, vol. 104, no. 41, pp. 16086-16091, 2007.

[51] C. A. Borgoño, I. P. Michael, J. L. V. Shaw et al., "Expression and functional characterization of the cancer-related serine protease, human tissue kallikrein 14," Journal of Biological Chemistry, vol. 282, no. 4, pp. 2405-2422, 2007.

[52] L. Bin, B. E. Kim, C. F. Hall, S. M. Leach, and D. Y. M. Leung, "Inhibition of transcription factor specificity protein 1 alters the gene expression profile of keratinocytes leading to upregulation of kallikrein-related peptidases and thymic stromal lymphopoietin," The Journal of Investigative Dermatology, vol. 131, no. 11, pp. 2213-2222, 2011.

[53] H. Takahashi, M. Nakazawa, K. Takahashi et al., "Effects of zinc deficient diet on development of atopic dermatitis-like eruptions in DS-Nh mice," Journal of Dermatological Science, vol. 50, no. 1, pp. 31-39, 2008.

[54] T. J. David, F. E. Wells, T. C. Sharpe, and A. C. C. Gibbs, "Low serum zinc in children with atopic eczema," The British Journal of Dermatology, vol. 111, no. 5, pp. 597-601, 1984.

[55] J. E. Kim, S. R. Yoo, M. G. Jeong, J. Y. Ko, and Y. S. Ro, “Hair zinc levels and the efficacy of oral zinc supplementation in patients with atopic dermatitis," Acta Dermato-Venereologica, vol. 94, no. 5, pp. 558-562, 2014.

[56] F. Rippke, V. Schreiner, T. Doering, and H. I. Maibach, "Stratum corneum $\mathrm{pH}$ in atopic dermatitis: impact on skin barrier function and colonization with Staphylococcus aureus," American Journal of Clinical Dermatology, vol. 5, no. 4, pp. 217-223, 2004.

[57] S. Kezic, G. M. O’Regan, R. Lutter et al., "Filaggrin loss-offunction mutations are associated with enhanced expression of IL-1 cytokines in the stratum corneum of patients with atopic dermatitis and in a murine model of filaggrin deficiency," Journal of Allergy and Clinical Immunology, vol. 129, no. 4, pp. 1031-1039.e1, 2012.

[58] K. Stefansson, M. Brattsand, D. Roosterman et al., "Activation of proteinase-activated receptor-2 by human kallikreinrelated peptidases," The Journal of Investigative Dermatology, vol. 128, no. 1, pp. 18-25, 2008.

[59] N. Kirschner, P. Houdek, M. Fromm, I. Moll, and J. M. Brandner, "Tight junctions form a barrier in human epidermis," European Journal of Cell Biology, vol. 89, no. 11, pp. 839-842, 2010.

[60] M. Furuse, M. Hata, K. Furuse et al., "Claudin-based tight junctions are crucial for the mammalian epidermal barrier: a lesson from claudin-1-deficient mice," The Journal of Cell Biology, vol. 156, no. 6, pp. 1099-1111, 2002.

[61] A. De Benedetto, N. M. Rafaels, L. Y. McGirt et al., "Tight junction defects in patients with atopic dermatitis," Journal of Allergy and Clinical Immunology, vol. 127, no. 3, pp. 773-786.e7, 2011.

[62] Y. Miyoshi, S. Tanabe, and T. Suzuki, "Cellular zinc is required for intestinal epithelial barrier maintenance via the regulation of claudin-3 and occludin expression," American Journal of Physiology. Gastrointestinal and Liver Physiology, vol. 311, no. 1, pp. G105-G116, 2016.

[63] M. N. Tatari, B. De Craene, B. Soen et al., "ZEB2-transgene expression in the epidermis compromises the integrity of the epidermal barrier through the repression of different tight junction proteins," Cellular and Molecular Life Sciences, vol. 71, no. 18, pp. 3599-3609, 2014.

[64] C. Becker-Pauly, M. Höwel, T. Walker et al., "The alpha and beta subunits of the metalloprotease meprin are expressed in separate layers of human epidermis, revealing different functions in keratinocyte proliferation and differentiation," The Journal of Investigative Dermatology, vol. 127, no. 5, pp. 1115-1125, 2007.

[65] I. Wessels, M. Maywald, and L. Rink, "Zinc as a gatekeeper of immune function," Nutrients, vol. 9, no. 12, 2017.

[66] W. Amano, S. Nakajima, H. Kunugi et al., "The Janus kinase inhibitor JTE-052 improves skin barrier function through suppressing signal transducer and activator of transcription 3 signaling," The Journal of Allergy and Clinical Immunology, vol. 136, no. 3, pp. 667-677.e7, 2015.

[67] J. Seltmann, L. M. Roesner, F. W. von Hesler, M. Wittmann, and T. Werfel, "IL-33 impacts on the skin barrier by downregulating the expression of filaggrin," Journal of Allergy and Clinical Immunology, vol. 135, no. 6, pp. 1659-1661.e4, 2015.

[68] W. I. Ryu, H. Lee, H. C. Bae et al., "IL-33 down-regulates CLDN1 expression through the ERK/STAT3 pathway in keratinocytes," Journal of Dermatological Science, vol. 90, no. 3, pp. 313-322, 2018.

[69] C. Cornelissen, Y. Marquardt, K. Czaja et al., "IL-31 regulates differentiation and filaggrin expression in human organotypic skin models," Journal of Allergy and Clinical Immunology, vol. 129, no. 2, pp. 426-433.e8, 2012.

[70] M. Merad, F. Ginhoux, and M. Collin, "Origin, homeostasis and function of Langerhans cells and other langerinexpressing dendritic cells," Nature Reviews Immunology, vol. 8, no. 12, pp. 935-947, 2008.

[71] L. Chorro, A. Sarde, M. Li et al., "Langerhans cell (LC) proliferation mediates neonatal development, homeostasis, and inflammation-associated expansion of the epidermal LC network," The Journal of Experimental Medicine, vol. 206, no. 13, pp. 3089-3100, 2009.

[72] G. Hoeffel, Y. Wang, M. Greter et al., "Adult Langerhans cells derive predominantly from embryonic fetal liver monocytes with a minor contribution of yolk sac-derived macrophages," The Journal of Experimental Medicine, vol. 209, no. 6, pp. 1167-1181, 2012.

[73] C. Schulz, E. G. Perdiguero, L. Chorro et al., "A lineage of myeloid cells independent of Myb and hematopoietic stem cells," Science, vol. 336, no. 6077, pp. 86-90, 2012.

[74] L. C. Davies, S. J. Jenkins, J. E. Allen, and P. R. Taylor, “Tissue-resident macrophages," Nature Immunology, vol. 14, no. 10, pp. 986-995, 2013.

[75] S. C. Zimmerli and C. Hauser, "Langerhans cells and lymph node dendritic cells express the tight junction component claudin-1," The Journal of Investigative Dermatology, vol. 127, no. 10, pp. 2381-2390, 2007.

[76] D. Y. Kitashima, T. Kobayashi, T. Woodring et al., "Langerhans cells prevent autoimmunity via expansion of keratinocyte antigen-specific regulatory T cells," eBioMedicine, vol. 27, pp. 293-303, 2018. 
[77] T. Kawamura, Y. Ogawa, Y. Nakamura et al., "Severe dermatitis with loss of epidermal Langerhans cells in human and mouse zinc deficiency," The Journal of Clinical Investigation, vol. 122, no. 2, pp. 722-732, 2012.

[78] E. Maverakis, M. A. Fung, P. J. Lynch et al., "Acrodermatitis enteropathica and an overview of zinc metabolism," Journal of the American Academy of Dermatology, vol. 56, no. 1, pp. 116-124, 2007.

[79] Y. Y. Yu, C. P. Kirschke, and L. Huang, "Immunohistochemical analysis of ZnT1, 4, 5, 6, and 7 in the mouse gastrointestinal tract," The Journal of Histochemistry and Cytochemistry, vol. 55, no. 3, pp. 223-234, 2006.

[80] X. Wang and B. Zhou, "Dietary zinc absorption: a play of Zips and ZnTs in the gut," IUBMB Life, vol. 62, no. 3, pp. 176-182, 2010.

[81] E. R. Lazarowski, R. C. Boucher, and T. K. Harden, "Mechanisms of release of nucleotides and integration of their action as P2X- and P2Y-receptor activating molecules," Molecular Pharmacology, vol. 64, no. 4, pp. 785-795, 2003.

[82] S. Koizumi, K. Fujishita, K. Inoue, Y. Shigemoto-Mogami, M. Tsuda, and K. Inoue, "Ca2+ waves in keratinocytes are transmitted to sensory neurons: the involvement of extracellular ATP and P2Y2 receptor activation," The Biochemical Journal, vol. 380, no. 2, pp. 329-338, 2004.

[83] N. Mizumoto, T. Kumamoto, S. C. Robson et al., "CD39 is the dominant Langerhans cell-associated ecto-NTPDase: modulatory roles in inflammation and immune responsiveness," Nature Medicine, vol. 8, no. 4, pp. 358-365, 2002.

[84] N. Mizumoto, M. E. Mummert, D. Shalhevet, and A. Takashima, "Keratinocyte ATP release assay for testing skin-irritating potentials of structurally diverse chemicals," The Journal of Investigative Dermatology, vol. 121, no. 5, pp. 1066-1072, 2003.

[85] J. G. Georgiou, K. K. Skarratt, S. J. Fuller et al., "Human epidermal and monocyte-derived Langerhans cells express functional P2X receptors," The Journal of Investigative Dermatology, vol. 125, no. 3, pp. 482-490, 2005.

[86] C. L. Ho, C. Y. Yang, W. J. Lin, and C. H. Lin, "Ecto-nucleoside triphosphate diphosphohydrolase 2 modulates local ATP-induced calcium signaling in human $\mathrm{HaCaT}$ keratinocytes," PLoS One, vol. 8, no. 3, article e57666, 2013.

[87] G. G. Yegutkin, "Nucleotide- and nucleoside-converting ectoenzymes: important modulators of purinergic signalling cascade," Biochimica et Biophysica Acta (BBA) - Molecular Cell Research, vol. 1783, no. 5, pp. 673-694, 2008.

[88] H. Zimmermann, "Extracellular metabolism of ATP and other nucleotides," Naunyn-Schmiedeberg's Archives of Pharmacology, vol. 362, no. 4-5, pp. 299-309, 2000.

[89] Y. Ogawa, M. Kinoshita, N. Mizumura et al., "Purinergic molecules in the epidermis," The Journal of Investigative Dermatology, vol. 138, no. 11, pp. 2486-2488, 2018.

[90] T. Takeda, S. Miyazaki, M. Kobayashi et al., "Zinc deficiency causes delayed ATP clearance and adenosine generation in rats and cell culture models," Communications Biology, vol. 1, no. 1, p. 113, 2018.

[91] M. Ladwein, U. Pape, D. Schmidt et al., "The cell-cell adhesion molecule EpCAM interacts directly with the tight junction protein claudin-7," Experimental Cell Research, vol. 309, no. 2, pp. 345-357, 2005.

[92] T. Ouchi, G. Nakato, and M. C. Udey, "EpCAM expressed by murine epidermal Langerhans cells modulates immunization to an epicutaneously applied protein antigen," The Journal of Investigative Dermatology, vol. 136, no. 8, pp. 1627-1635, 2016.

[93] S. Konradi, N. Yasmin, D. Haslwanter et al., "Langerhans cell maturation is accompanied by induction of $\mathrm{N}$-cadherin and the transcriptional regulators of epithelial-mesenchymal transition ZEB1/2," European Journal of Immunology, vol. 44, no. 2, pp. 553-560, 2014.

[94] J. Comijn, G. Berx, P. Vermassen et al., "The twohanded E box binding zinc finger protein SIP1 downregulates E-cadherin and induces invasion," Molecular Cell, vol. 7, no. 6, pp. 1267-1278, 2001.

[95] T. A. Borkowski, J. J. Letterio, A. G. Farr, and M. C. Udey, "A role for endogenous transforming growth factor beta 1 in Langerhans cell biology: the skin of transforming growth factor beta 1 null mice is devoid of epidermal Langerhans cells," The Journal of Experimental Medicine, vol. 184, no. 6, pp. 2417-2422, 1996.

[96] D. H. Kaplan, M. O. Li, M. C. Jenison, W. D. Shlomchik, R. A. Flavell, and M. J. Shlomchik, "Autocrine/paracrine TGFbeta1 is required for the development of epidermal Langerhans cells," The Journal of Experimental Medicine, vol. 204, no. 11, pp. 2545-2552, 2007.

[97] J. M. Kel, M. J. H. Girard-Madoux, B. Reizis, and B. E. Clausen, "TGF-beta is required to maintain the pool of immature Langerhans cells in the epidermis," Journal of Immunology, vol. 185, no. 6, pp. 3248-3255, 2010.

[98] A. Bobr, B. Z. Igyarto, K. M. Haley, M. O. Li, R. A. Flavell, and D. H. Kaplan, "Autocrine/paracrine TGF- $\beta 1$ inhibits Langerhans cell migration," Proceedings of the National Academy of Sciences of the United States of America, vol. 109, no. 26, pp. 10492-10497, 2012.

[99] Z. Yang, Z. Mu, B. Dabovic et al., "Absence of integrinmediated TGFbetal activation in vivo recapitulates the phenotype of TGFbeta1-null mice," The Journal of Cell Biology, vol. 176, no. 6, pp. 787-793, 2007.

[100] P. Aluwihare, Z. Mu, Z. Zhao et al., "Mice that lack activity of $\alpha v \beta 6$ - and $\alpha v \beta 8$-integrins reproduce the abnormalities of Tgfb1- and Tgfb3-null mice," Journal of Cell Science, vol. 122, no. 2, pp. 227-232, 2008.

[101] J. Mohammed, L. K. Beura, A. Bobr et al., "Stromal cells control the epithelial residence of DCs and memory $\mathrm{T}$ cells by regulated activation of TGF- $\beta$," Nature Immunology, vol. 17, no. 4, pp. 414-421, 2016.

[102] Y. Inoue, S. Hasegawa, S. Ban et al., "ZIP2 protein, a zinc transporter, is associated with keratinocyte differentiation," The Journal of Biological Chemistry, vol. 289, no. 31, pp. 21451-21462, 2014.

[103] E. Emri, E. Miko, P. Bai et al., "Effects of non-toxic zinc exposure on human epidermal keratinocytes," Metallomics, vol. 7, no. 3, pp. 499-507, 2015.

[104] D. Wilson, G. Varigos, and M. L. Ackland, "Apoptosis may underlie the pathology of zinc-deficient skin," Immunology and Cell Biology, vol. 84, no. 1, pp. 28-37, 2006.

[105] A. Gueniche, J. Viac, G. Lizard, M. Charveron, and D. Schmitt, "Protective effect of zinc on keratinocyte activation markers induced by interferon or nickel," Acta Dermato-Venereologica, vol. 75, no. 1, pp. 19-23, 1995.

[106] J. Yamaoka, T. Kume, A. Akaike, and Y. Miyachi, "Suppressive effect of zinc ion on iNOS expression induced by interferon-gamma or tumor necrosis factor-alpha in murine 
keratinocytes," Journal of Dermatological Science, vol. 23, no. 1, pp. 27-35, 2000.

[107] V. Jarrousse, N. Castex-Rizzi, A. Khammari, M. Charveron, and B. Dréno, "Zinc salts inhibit in vitro Toll-like receptor 2 surface expression by keratinocytes," European Journal of Dermatology, vol. 17, no. 6, pp. 492-496, 2007.

[108] T. Kambe, T. Tsuji, A. Hashimoto, and N. Itsumura, "The physiological, biochemical, and molecular roles of zinc transporters in zinc homeostasis and metabolism," Physiological Reviews, vol. 95, no. 3, pp. 749-784, 2015.

[109] M. A. Hediger, M. F. Romero, J. B. Peng, A. Rolfs, H. Takanaga, and E. A. Bruford, "The ABCs of solute carriers: physiological, pathological and therapeutic implications of human membrane transport proteins," Pflügers Archiv European Journal of Physiology, vol. 447, no. 5, pp. 465-468, 2004.

[110] R. D. Palmiter and L. Huang, "Efflux and compartmentalization of zinc by members of the SLC30 family of solute carriers," Pflügers Archiv European Journal of Physiology, vol. 447, no. 5, pp. 744-751, 2004.

[111] D. J. Eide, “The SLC39 family of metal ion transporters," Pflügers Archiv European Journal of Physiology, vol. 447, no. 5, pp. 796-800, 2004.

[112] H. Tapiero and K. D. Tew, "Trace elements in human physiology and pathology: zinc and metallothioneins," Biomedicine \& Pharmacotherapy, vol. 57, no. 9, pp. 399-411, 2003.

[113] M. Lazarczyk, C. Pons, J. A. Mendoza, P. Cassonnet, Y. Jacob, and M. Favre, "Regulation of cellular zinc balance as a potential mechanism of EVER-mediated protection against pathogenesis by cutaneous oncogenic human papillomaviruses," The Journal of Experimental Medicine, vol. 205, no. 1, pp. 35-42, 2008.

[114] N. Ramoz, M. Favre, G. Orth et al., "Evidence for a nonallelic heterogeneity of epidermodysplasia verruciformis with two susceptibility loci mapped to chromosome regions 2p21-p 24 and 17q25," The Journal of Investigative Dermatology, vol. 114, no. 6, pp. 1148-1153, 2000.

[115] N. Ramoz, L. A. Rueda, B. Bouadjar, L. S. Montoya, G. Orth, and M. Favre, "Mutations in two adjacent novel genes are associated with epidermodysplasia verruciformis," Nature Genetics, vol. 32, no. 4, pp. 579-581, 2002.

[116] B. H. Bin, J. Bhin, N. H. Kim et al., "An acrodermatitis enteropathica-associated $\mathrm{Zn}$ transporter, ZIP4, regulates human epidermal homeostasis," The Journal of Investigative Dermatology, vol. 137, no. 4, pp. 874-883, 2017.

[117] B. H. Bin, J. Bhin, M. Takaishi et al., "Requirement of zinc transporter ZIP10 for epidermal development: implication of the ZIP10-p 63 axis in epithelial homeostasis," Proceedings of the National Academy of Sciences of the United States of America, vol. 114, no. 46, pp. 12243-12248, 2017.

[118] G. L. Sen, L. D. Boxer, D. E. Webster et al., “ZNF750 is a p 63 target gene that induces KLF4 to drive terminal epidermal differentiation," Developmental Cell, vol. 22, no. 3, pp. 669677, 2012.

[119] J. J. van den Oord and M. De Ley, "Distribution of metallothionein in normal and pathological human skin," Archives of Dermatological Research, vol. 286, no. 1, pp. 62-68, 1994.
[120] K. Hanada, D. Sawamura, I. Hashimoto, K. Kida, and A. Naganuma, "Epidermal proliferation of the skin in metallothionein-null mice," The Journal of Investigative Dermatology, vol. 110, no. 3, pp. 259-262, 1998.

[121] A. Zamirska, L. Matusiak, P. Dziegiel, G. Szybejko-Machaj, and J. C. Szepietowski, "Expression of metallothioneins in cutaneous squamous cell carcinoma and actinic keratosis," Pathology Oncology Research, vol. 18, no. 4, pp. 849-855, 2012. 


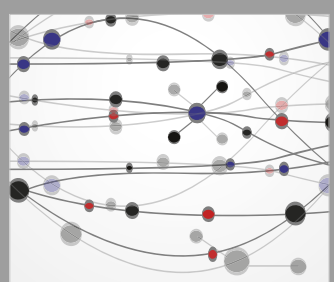

The Scientific World Journal
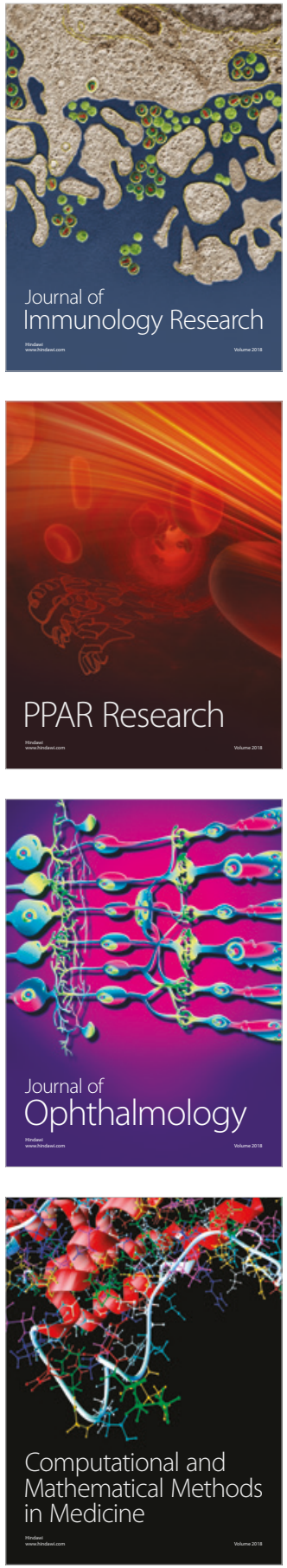

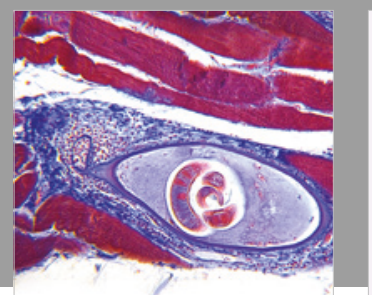

Gastroenterology Research and Practice

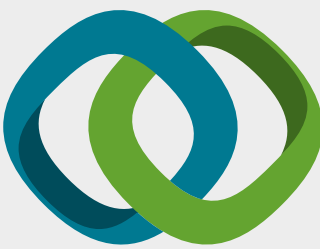

\section{Hindawi}

Submit your manuscripts at

www.hindawi.com
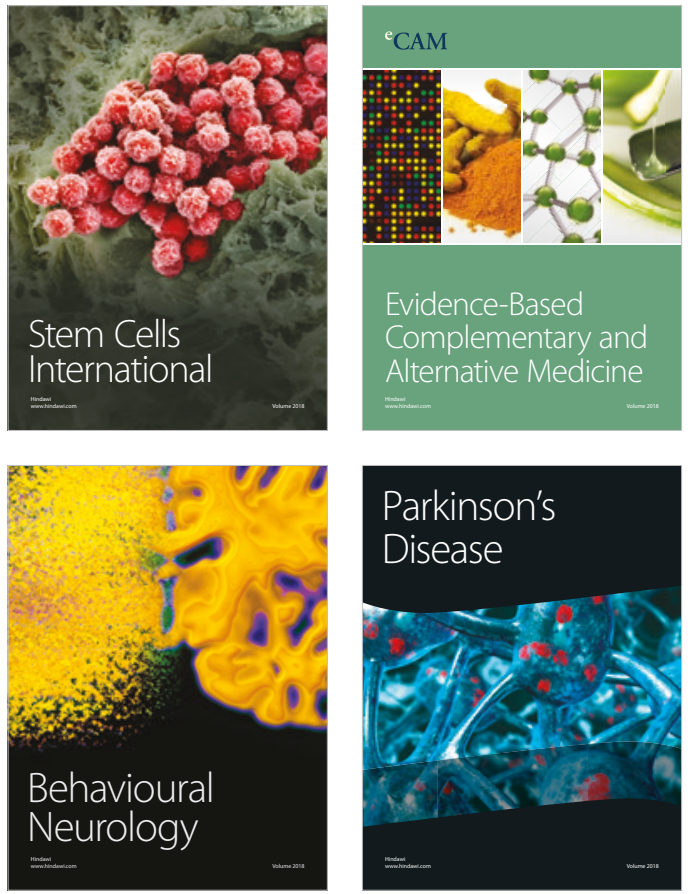

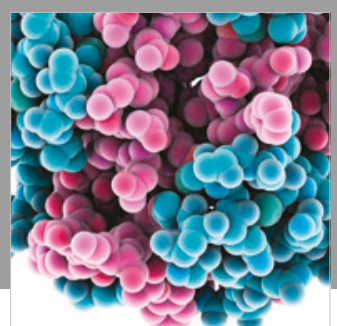

ournal of

Diabetes Research

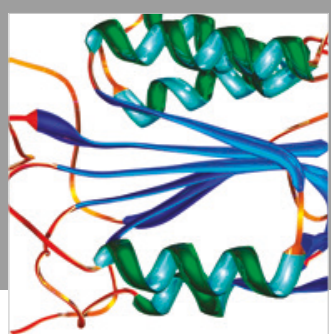

Disease Markers
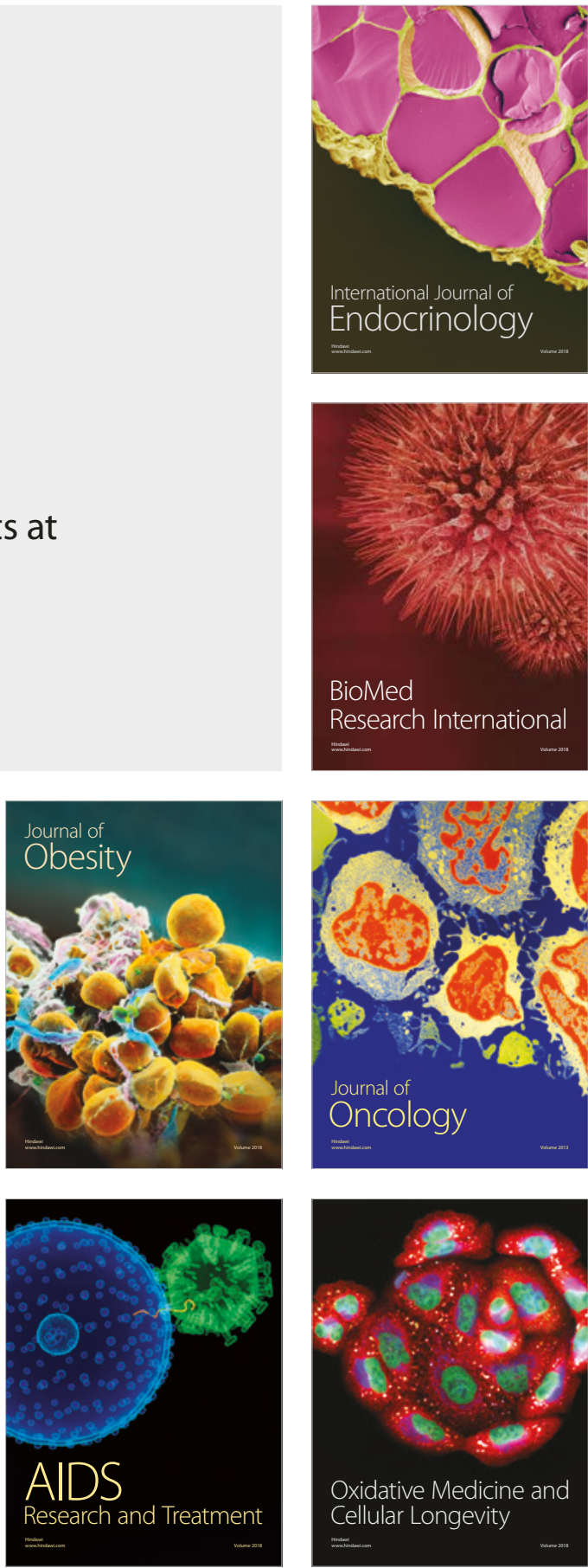